\title{
Effects of cisplatin on surgically induced endometriosis in a rat model
}

\author{
ZHANFEI LI ${ }^{1,2}$, HUIBING LIU ${ }^{1}$, JINGHE LANG ${ }^{2}$, GUORUI ZHANG ${ }^{2}$ and ZHENGXING HE ${ }^{2}$ \\ ${ }^{1}$ Department of Obstetrics and Gynecology, Nanfang Hospital, Southern Medical University, Guangzhou, Guangdong 510515; \\ ${ }^{2}$ Department of Obstetrics and Gynecology, Peking Union Medical College Hospital, Beijing 100005, P.R. China
}

Received March 29, 2016; Accepted May 22, 2018

DOI: $10.3892 / \mathrm{ol} .2018 .9275$

\begin{abstract}
Research has strongly suggested that the features of endometriosis serve as a precursor lesion of ovarian cancer. Cisplatin (CDDP) is the preferred drug against these cancer types. The present study investigated the effects of CDDP on surgically induced endometriosis in a rat model. Endometriosis was surgically induced by the autologous transplantation of endometrial tissue. A total of 36 model rats were randomly divided into three groups. The rats in Group 1 (control group, $\mathrm{n}=12)$ received no medication. The rats in Group $2(\mathrm{n}=12)$ and Group $3(\mathrm{n}=12)$ were administered $35 \mathrm{mg} / \mathrm{m}^{2}$ CDDP and $70 \mathrm{mg} / \mathrm{m}^{2} \mathrm{CDDP}$, respectively, every four days. All rats were treated for a total of 24 days. The growth and histologic scores of the implants were calculated. The expression of protein markers, including vascular endothelial growth factor (VEGF), aromatase P450 (P450arom), transforming growth factor- $\beta$ (TGF- $\beta$ ) and matrix metalloproteinase (MMP)-2, were assessed using immunohistochemistry, an enzyme-linked immunosorbent assay and western blot analysis. Following CDDP treatment, the mean implant sizes were significantly reduced in Groups 2 and 3 compared with the control group $(\mathrm{P}=0.01)$. The mean histologic scores were also significantly lower in Groups 2 and 3. Furthermore, the protein expression of VEGF, P450arom, TGF- $\beta$ and MMP-2 was significantly lower in Groups 2 and 3 when compared with the control group. A loss of hair was observed in 4 rats, which only occurred in Group 3. A dose-dependent effect was observed in the two CDDP-treated groups. In conclusion, the expression of proliferation- and angiogenesis-associated proteins was significantly lower following treatment with CDDP. CDDP caused a significant regression in the size of the endometriotic implants and induced atrophy of these lesions in rats.
\end{abstract}

Correspondence to: Dr Jinghe Lang, Department of Obstetrics and Gynecology, Peking Union Medical College Hospital, 1 Shuaifuyuan, Beijing 100005, P.R. China

E-mail: langjhpumch@163.com

Key words: endometriosis, cisplatin, rat model, chemotherapy, treatment

\section{Introduction}

Endometriosis is a complicated and chronic disease that has been debated for decades. Although it is known to be estrogen dependent and an estrogen-inhibiting therapy has been identified to be beneficial, the exact etiopathology of endometriosis is, at present, not clear $(1,2)$. Gonadotropin-releasing hormone agonist and gestrinone are able to suppress the ectopic growth of endometrial tissue and are frequently used to treat endometriosis (3). However, these hormone drugs are associated with high recurrence rates and side effects, which limit their long-term use (4). There has been no optimal treatment method for endometriosis so far.

Although endometriosis is not a malignant disease, it has been reported that endometriosis and ovarian cancer are associated at the molecular level (5). The association between endometriosis and cancer is a matter of growing concern (6). With the progress of endometriosis research, histological, biochemical and epidemiological studies have identified the features of endometriosis as a precursor lesion of ovarian cancer (7-14). Genetic research has also identified gene mutations directly associated with neoplasms in endometriotic lesions, including the AT-rich interaction domain 1A, KRAS, p53 and phosphatase and tensin homolog genes (15).

Endometrioid adenocarcinoma and clear cell adenocarcinoma are the two most common pathological types of cancer resulting from the malignant transformation of endometriosis (16). Cisplatin (CDDP) is the most widely used drug in the treatment of ovarian cancer and endometrial carcinoma. CDDP-based chemotherapy is the preferred method against these cancer types (17-19). The anti-neoplastic activity of CDDP is a result of its binding to DNA in target cells to induce DNA cross-links (20). CDDP was also demonstrated to induce the downregulation of parkin-like cytoplasmic protein and apoptosis in the target cells through a p53-associated pathway; this is hypothesized to be associated with its anti-neoplastic mechanism (21).

To the best of our knowledge there has been no study conducted to demonstrate the effects of CDDP in an endometriosis rat model. Therefore, the aim of the present study was to investigate the effects of CDDP on endometriotic tissue and the expression of proliferation- and angiogenesis-associated proteins in a rat model of endometriosis. 


\section{Materials and methods}

Mouse model. A total of 36 female Sprague-Dawley rats maintained in a specific pathogen-free (SPF) facility (8 weeks old and weighing 200-235 g) were purchased from Peking Union Medical College and the Institute of Laboratory Animal Science, Chinese Academy of Medical Science (Beijing, China). The rats were sacrificed using abdominal aortic bleeding. The present study was approved by the Institutional Animal Care and Use Committee of the Institute of Laboratory Animal Science, and the research was conducted in accordance with the institutional guidelines (22). All the rats were caged in pairs in a SPF facility, temperature $20-26^{\circ} \mathrm{C}$, relative humidity $40-70 \%$, with a 12 -h light/dark cycle and ad libitum access to food and water (23).

Experimental procedures and tissue collection. All the rats underwent three consecutive surgical procedures. The rats were anesthetized via intraperitoneal administration of $3 \%$ pentobarbital sodium (Sigma-Aldrich; Merck KGaA, Darmstadt, Germany) at a dose of $35 \mathrm{mg} / \mathrm{kg}$.

Procedure 1. In order to observe the estrous cycles of rats, vaginal smears were obtained and subject to Papanicolaou staining, as previously described (24). When the rat was in estrus, endometriosis was surgically induced according to the method described by Körbel et al with slight modifications (25). Under aseptic conditions, the rat's abdominal skin was shaved and a ventral midline incision $\sim 5 \mathrm{~cm}$ long was created to open the abdominal cavity. The left uterine horn was ligated and excised, and the excised uterine horn was placed in normal saline. The serosal (outer) layer of the excised segment was removed, and the uterine segment was trimmed into a $5 \times 5 \mathrm{~mm}^{2}$ piece. Next, the endometrial piece was sutured to the inner side of the abdominal wall, with the endometrial surface facing the peritoneal cavity. Finally, the abdominal muscles and skin were sutured.

Procedure 2. Following the surgical induction of endometriosis, all rats were allowed to recover for 4 weeks, during which period they were not administered any medication. All 36 animals survived. A second exploratory laparotomy was performed on each rat to observe the growth of the endometriotic implants. The peritoneal cavity was irrigated with $5 \mathrm{ml}$ normal saline. The peritoneal fluid obtained was centrifuged at $1,000 \mathrm{x}$ g for $20 \mathrm{~min}$ at room temperature and the solution obtained was stored at $-20^{\circ} \mathrm{C}$. The surface areas of the implants were measured (length $[\mathrm{mm}] \mathrm{x}$ width $[\mathrm{mm}]$ ). The endometriotic lesions were photographed, and the lesion sizes were recorded. Finally, the peritoneal cavity was closed.

Procedure 3. All rats were allowed to rest for three days following the second procedure. The 36 rats were then randomly divided into three groups of twelve rats each. There was no significant difference in the area of the implants between the groups prior to the treatment (Table I). The rats in Group $1(\mathrm{n}=12)$ served as controls and were administered $1 \mathrm{ml}$ of normal saline daily via peritoneal perfusion. The rats in Group $2(\mathrm{n}=12)$ were administered $35 \mathrm{mg} / \mathrm{m}^{2} \mathrm{CDDP}$ via peritoneal perfusion every 4 days. The rats in Group $3(n=12)$ were administered $70 \mathrm{mg} / \mathrm{m}^{2} \mathrm{CDDP}$ via peritoneal perfusion every 4 days. The skin surface areas of the rats were measured using the Meeh-Rubner equation $\mathrm{A}=\mathrm{Kx}\left(\mathrm{W}^{2 / 3} / 10000\right)$, where A is the skin surface area $\left(\mathrm{m}^{2}\right)$, the $\mathrm{K}$ value is 9.1 for rats, and $\mathrm{W}$ is the body weight (g) (26). CDDP in the powder form (Sigma-Aldrich; Merck KGaA) was crushed and dissolved in normal saline. All rats were treated for a total of 24 days, which was equivalent to 6 estrous cycles. A total of 4 days after the final treatment, a third laparotomy was performed. The rats were anesthetized with $3 \%$ pentobarbital sodium $(50 \mathrm{mg} / \mathrm{kg})$, and the abdominal cavity was opened. Then, the implants were measured (length [mm] x width [mm]) and photographed. The peritoneal cavity was then irrigated with $5 \mathrm{ml}$ normal saline and the peritoneal fluid obtained was centrifuged at $1,000 \mathrm{xg}$ for $20 \mathrm{~min}$ at room temperature, and the solution was stored at $-20^{\circ} \mathrm{C}$. Finally, the implants were excised, and a portion of the endometriotic implant was fixed in formalin for histopathological examination and immunohistochemistry (IHC). The remainder of the endometriotic implant was fixed in liquid nitrogen and stored at $-80^{\circ} \mathrm{C}$ for further analyses.

Histopathological examination and IHC. In procedure 3, the endometriotic implants were excised following the rats being sacrificed, and then the implants were fixed in the formalin solution at $4^{\circ} \mathrm{C}$ for one month. Subsequently, the implants were embedded in paraffin and were sliced at $4-\mu \mathrm{m}$ thickness. Hematoxylin and eosin staining was used for histopathological examination. Subsequently, for the IHC analysis process, the slides were deparaffinized and rehydrated in ethanol (ethanol concentrations: $100,95,80$ and $70 \%$ ); this was followed by steaming in sodium citrate buffer (cat. no. ZLI-9065; Beijing Noble Technology Co., Ltd., Beijing, China). Then, the slides were incubated in a $3 \% \mathrm{H}_{2} \mathrm{O}_{2}$ solution at $26^{\circ} \mathrm{C}$ for $15 \mathrm{~min}$ to deactivate endogenous peroxidase and washed with phosphate-buffered saline twice for $5 \mathrm{~min}$ each time. Once the nonspecific antigens were blocked at $26^{\circ} \mathrm{C}$ for 60 min using normal goat serum (1:20; cat. no. SL038; Beijing Solarbio Science \& Technology Co., Ltd., Beijing, China), the slides were incubated with primary antibodies overnight at $4^{\circ} \mathrm{C}$. The primary antibodies included rabbit anti-rat vascular endothelial growth factor (VEGF; cat. no. Ab14078), aromatase P450 (P450arom; cat. no. Ab34193), transforming growth factor- $\beta$ (TGF- $\beta$; cat. no Ab66043) and matrix metalloproteinase (MMP)-2 polyclonal antibodies (cat. no. Ab110186) (1:100; Abcam, Cambridge, UK). The slides were washed and then incubated with the horseradish peroxidase (HRP)-conjugated goat anti-rabbit IgG $\mathrm{H} \& \mathrm{~L}$ secondary antibodies at $26^{\circ} \mathrm{C}$ for 30 min (1:200; cat. no. Ab6721; Abcam); this was followed by counterstaining with hematoxylin $(0.2 \%)$ using the $\mathrm{ABC}$ kit (Abcam) according to the manufacturer's protocol. For semi-quantitative analysis, the researcher assessing the slides was blinded to all the groups. The slides were evaluated as described previously (27). According to the percentage of cells that stained positive, the following scores from 0 to 3 were assigned: $0:<5 \%, 1: 5-25 \%, 2: 26-50 \%$, and 3: $>50 \%$. The staining intensity of the cells was scored as follows: 0 : Negative, 1 : Weakly positive, 2 : Moderately positive, and 3: Strongly positive. The IHC score for each rat was determined by multiplying the two scores (staining intensity and percentage of cells stained). 
Table I. Treatment results and comparisons of the study groups.

Measures Group 1 (control) Group 2 (35 mg/m² CDDP) Group $3\left(70 \mathrm{mg} / \mathrm{m}^{2} \mathrm{CDDP}\right) \quad$ P-value

Number of rats

Mean surface area of implants $\left(\mathrm{mm}^{2}\right)$

Prior to medication

Following medication

Histopathological score of implants

VEGF level in peritoneal fluid (pg/ml)

Prior to medication

Following medication

12

$\begin{array}{rr}38.17 \pm 8.61 & 36.08 \pm 6.89 \\ 47.08 \pm 8.27 & 18.67 \pm 2.99 \\ 2.50 \pm 0.67 & 1.67 \pm 0.65\end{array}$

$38.17 \pm 8.61$

$2.50 \pm 0.67$

$278.33 \pm 19.90$

$324.84 \pm 53.55$
12

$289.37 \pm 12.30$

$168.91 \pm 24.79$
12

$$
\begin{gathered}
37.92 \pm 4.72 \\
6.50 \pm 2.01 \\
0.90 \pm 0.57
\end{gathered}
$$

0.01

Values are given as mean \pm standard deviation. CDDP, cisplatin; VEGF, vascular endothelial growth factor.

Enzyme-linked immunosorbent assay (ELISA). The concentration of VEGF in the peritoneal fluid samples and the concentrations of VEGF, P450arom, TGF- $\beta$ and MMP-2 in the endometriotic implants were assayed using ELISA kits (cat. no. K2649R, K2652R, K2763R and K2337R, respectively; R\&D Systems, Inc., Minneapolis, MN, USA), according to the manufacturer's protocol. The endometriotic implant samples were homogenized and lysed in phosphate-buffered saline at $4^{\circ} \mathrm{C}$ for $60 \mathrm{~min}$. Whole-tissue lysates were obtained by subsequent centrifugation at $1,000 \mathrm{x}$ g at $4^{\circ} \mathrm{C}$ for $20 \mathrm{~min}$ and then stored at $-20^{\circ} \mathrm{C}$. Double replicates of each sample were run in each assay. The lower detection limits for the ELISA kits were $<1.5 \mathrm{pg} / \mathrm{ml}$ (VEGF), <1.5 U/1 (P450arom), <0.1 ng/ml (MMP-2) and $<1.5 \mathrm{pg} / \mathrm{ml}(\mathrm{TGF}-\beta)$.

Western blot analysis. Endometriotic implant samples were homogenized using the Fluka Tissue Grinder and lysed in cold radioimmunoprecipitation assay buffer for $20 \mathrm{~min}$ at $4^{\circ} \mathrm{C}$ (cat. no. BDIT0037; Beijing Biodragon Immunotechnologies Co., Ltd., Beijing, China). Tissue lysates were collected and centrifuged at $5,000 \mathrm{x}$ g for $20 \mathrm{~min}$ at $4^{\circ} \mathrm{C}$. Protein levels were detected using the BCA Protein assay kit with bovine serum albumin $(5 \mathrm{mg} / \mathrm{ml})$ as the standard (cat. no. BDIT0101; Beijing Biodragon Immunotechnologies Co., Ltd.). Protein lysate samples (50 $\mu \mathrm{g}$ each) were separated on a $12 \%$ SDS-PAGE gel and were subsequently transferred onto a nitrocellulose membrane. Following blocking with a $3 \%$ bovine serum albumin at $26^{\circ} \mathrm{C}$ for $30 \mathrm{~min}$ (cat. no. BF03075; Beijing Biodragon Immunotechnologies Co., Ltd.), the membranes were incubated overnight at $4^{\circ} \mathrm{C}$ with primary antibodies. The primary antibodies included rabbit anti-P450arom polyclonal antibody (1:1,000; cat. no. Ab18995; Abcam), rabbit anti-VEGF polyclonal antibody (1:1,000; cat. no. Ab46154; Abcam) and mouse anti- $\beta$-actin monoclonal antibody (1:5,000; cat. no. TDY041; Beijing TDY Biotech Co., Ltd., Beijing, China), which was used as the internal standard. Then, the membranes were washed and incubated with a goat anti-rabbit secondary antibody conjugated to horseradish peroxidase at $26^{\circ} \mathrm{C}$ for $40 \mathrm{~min}(1: 10,000$; cat. no. S004; Beijing TDY Biotech Co., Ltd.). Immunodetection was performed based on chemiluminescence (ECL reagent; EMD Millipore, Billerica, MA, USA. Protein-antibody complexes were quantified using the Bio-Rad Quantity One software, version 4.6.9 (Bio-Rad Laboratories, Inc., Hercules, CA, USA).

Statistical analysis. Statistical analyses were performed using SPSS 11.0 (SPSS, Inc., Chicago, IL, USA). Values were expressed as mean \pm standard deviation. Multiple comparisons were performed using a one-way analysis of variance and post-hoc Tukey's test. Non-normally distributed variables were analyzed using Kruskal-Wallis test and Mann-Whitney U-test. $\mathrm{P}<0.05$ was considered to indicate a statistically significant difference.

\section{Results}

Side effects and survival. Following peritoneal administration of CDDP for 15 days, 4 rats in Group 3 exhibited hair loss, which continued until the last day of the medication, and a similar phenomenon was not observed in the other two groups. All rats survived until the day of sacrifice.

Growth of endometriotic tissues. The formation of cystic and vascularized endometriotic tissues was successfully induced in all 36 rats. The mean surface area of the endometriotic implants was similar in all the groups prior to treatment (P>0.05; Table I). However, at the end of the treatment, the mean area of the implants in the CDDP groups were significantly reduced, compared with that in the control group $(\mathrm{P}<0.05$; Table I). The mean surface area of the endometriotic implants following medication demonstrated a significant decrease in Group 2 (from $36.08 \pm 6.89$ to $18.67 \pm 2.99 \mathrm{~mm}^{2}$; $\mathrm{P}<0.05$ ) and in Group 3 (from $37.92 \pm 4.72$ to $6.50 \pm 2.01 \mathrm{~mm}^{2}$; $\mathrm{P}<0.05$ ), but it non-significantly increased in Group 1 (from $38.17 \pm 8.61$ to $47.08 \pm 8.27 \mathrm{~mm}^{2} ; \mathrm{P}>0.05$ ) compared with prior to medication. In addition, the decrease in the mean surface area was significantly greater in Group 3 compared with in Group $2(\mathrm{P}<0.05)$. Macroscopic images of the endometriotic implants are presented in Fig. 1.

HE staining of the implant sections revealed the presence of ectopic epithelium. The growth of the epithelium in the endometrial explants was scored as follows: 3, well-preserved epithelium; 2, moderately preserved epithelium; 1 , poorly 

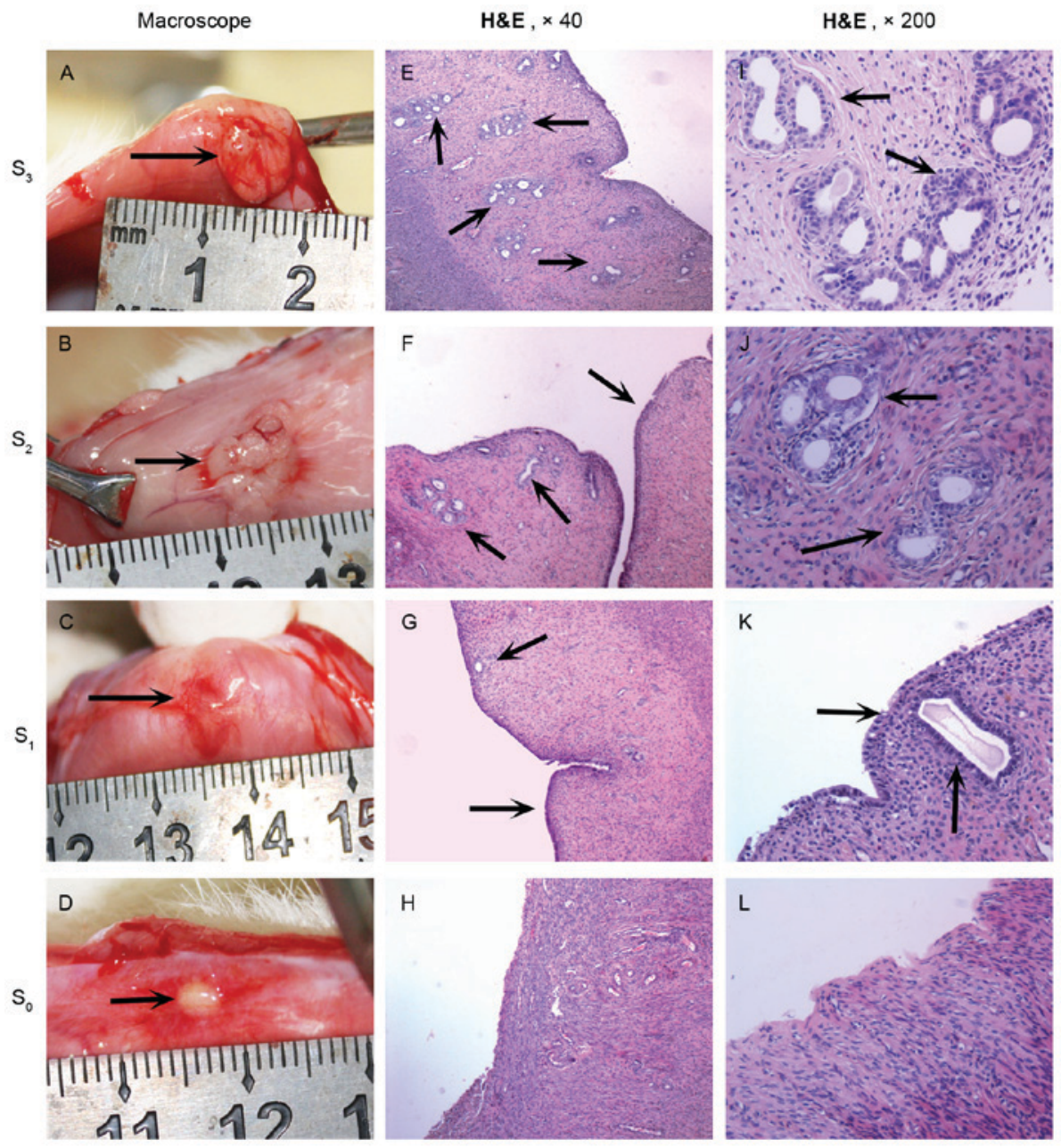

Figure 1. Representative images of the endometriotic tissues after the medication. (A) Macroscopic view of $\mathrm{S}_{3}$. (B) Macroscopic view of $\mathrm{S}_{2}$. (C) Macroscopic view of $S_{1}$. (D) Macroscopic view of $S_{0}$. The arrows indicate the macroscopic appearance of the endometriotic tissues and the histopathological view of the epithelium tissues. $\mathrm{S}_{3}$ : Score 3, well-preserved epithelial layer; $\mathrm{S}_{2}$ : Score 2, moderately preserved epithelium; $\mathrm{S}_{1}$ : Score 1, poorly preserved epithelium; $\mathrm{S}_{0}$ : Score 0, no epithelium. (E) $\mathrm{S}_{3}$, (F) $\mathrm{S}_{2},(\mathrm{G}) \mathrm{S}_{1}$ and (H) $\mathrm{S}_{0} \mathrm{H} \& \mathrm{E}$ staining at magnification x40. (I) $\mathrm{S}_{3},(J) \mathrm{S}_{2}$, (K) $\mathrm{S}_{1}$ and (L) $\mathrm{S}_{0} \mathrm{H} \& \mathrm{E}$ staining at magnification x200; H\&E, hematoxylin and eosin.

preserved epithelium (occasional epithelial cells only); and 0 , no epithelium. This scoring system was based on a previously published study for rat endometriosis (28). The mean histopathological score of the implants at the end of the treatment was significantly lower in Group $3(0.90 \pm 0.57)$ compared with in Group $2(1.67 \pm 0.65 ; \mathrm{P}<0.05$; Table I). The mean histopathological score in Group 2 was significantly lower compared with in Group $1(2.50 \pm 0.67 ; \mathrm{P}<0.05$; Table I). The representative images from staining of the endometriotic implants based on the histologic assessment are presented in Fig. 1.

IHC expression of VEGF, P450arom, MMP-2 and TGF- $\beta$ in endometriotic tissues. In the endometriotic tissues, the VEGF protein was present mainly in the vascular endothelial cells, and P450arom was present mainly in the glandular epithelial cells. The expression levels of the VEGF and P450arom proteins were significantly lower in Group $2(3.00 \pm 0.74$ and $3.25 \pm 0.87$, respectively) and Group 3 (1.25 \pm 0.45 and $1.08 \pm 0.29$, respectively) compared with in Group $1(4.33 \pm 0.78$ and $4.50 \pm 0.90$, respectively; $\mathrm{P}<0.05$ ). Furthermore, the VEGF and P450arom levels were significantly lower in Group 3 compared with in Group $2(\mathrm{P}<0.05)$. The IHC expression of VEGF and P450arom proteins in the endometriotic tissues is presented in Fig. $2 \mathrm{~A}-\mathrm{C}$ and D-F, respectively. The TGF- $\beta$ proteins were observed in the endometrial epithelium, and the MMP-2 proteins were principally located in the mesenchymal tissue. The IHC expression of TGF- $\beta$ and MMP- 2 was significantly lower in Group 2 (3.01 \pm 0.60 and $2.67 \pm 0.65$, respectively) and Group 3 (1.17 \pm 0.39 and $0.92 \pm 0.29$, respectively) compared with in Group $1(4.23 \pm 0.71$ and $4.92 \pm 0.79$ respectively; $\mathrm{P}<0.05)$. Furthermore, TGF- $\beta$ and MMP-2 expression was significantly lower in Group 3 compared with in Group $2(\mathrm{P}<0.05)$. The IHC expression of TGF- $\beta$ and MMP- 2 proteins in the endometriotic tissues is presented in Fig. 2G-I and J-L, respectively. Comparison of the IHC scores of VEGF and P450arom proteins between the groups is presented in Fig. 3A and B. Comparison of the IHC scores of TGF- $\beta$ and MMP-2 proteins between the groups is presented in Fig. $3 \mathrm{C}$ and D.

VEGF level in the peritoneal fluid and VEGF, P450arom, TGF- $\beta$ and MMP-2 levels in endometriotic tissues. The VEGF level in the peritoneal fluid was similar in all groups prior to administration of CDDP/saline (Table I). Following treatment, 

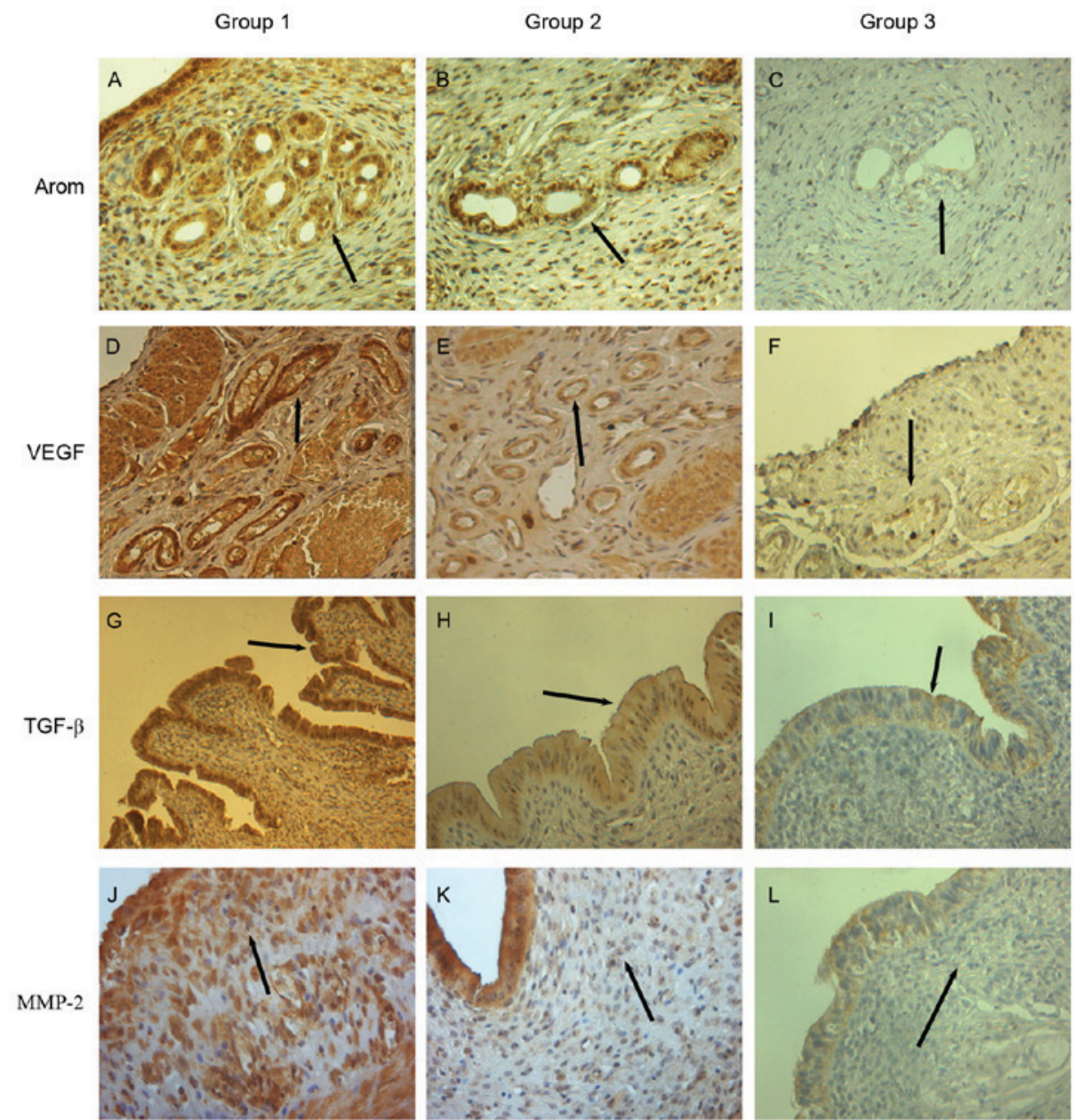

Figure 2. Representative images of immunohistochemical staining in the endometriotic tissues of rats. P450arom expression in glandular epithelium for (A) Group 1, (B) 2 and (C) 3; VEGF expression in vascular epithelium for (D) Group 1, (E) 2 and (F) 3; TGF- $\beta$ expression in endometrium epithelium for (G) Group 1, (H) 2 and (I) 3; MMP-2 expression in mesenchymal tissue for (J) Group 1, (K) 2 and (L) 3. VEGF, vascular endothelial growth factor; P450arom, aromatase P450; TGF- $\beta$, transforming growth factor- $\beta$; MMP- 2 , matrix metalloproteinase 2 . All the images were recorded at magnification $\times 200$.
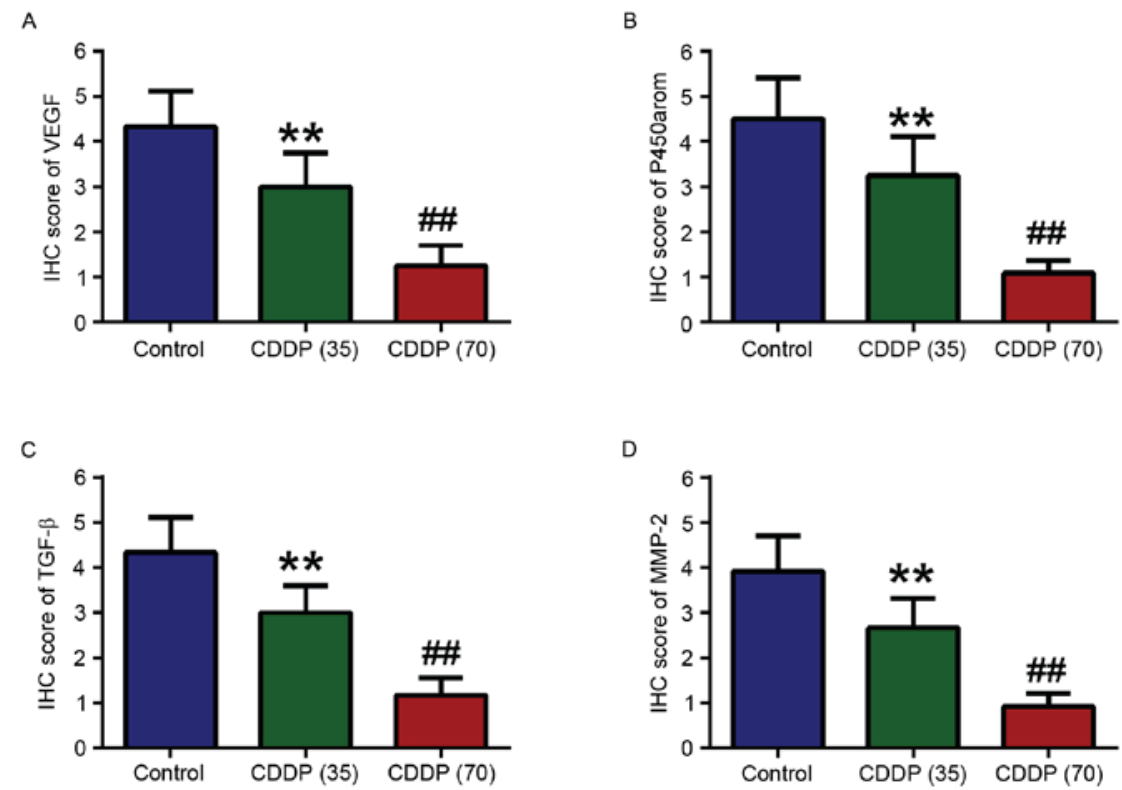

Figure 3. Comparisons of the IHC scores of VEGF, P450arom, TGF- $\beta$ and MMP-2 proteins between the groups. The IHC score values of (A) VEGF, (B) P450arom, (C) TGF- $\beta$ and (D) MMP-2 proteins in the endometriotic tissues were presented as the mean \pm standard deviation. Control: Group 1; CDDP (35): Group 2, CDDP dosage is $35 \mathrm{mg} / \mathrm{m}^{2}$; CDDP (70): Group 3, CDDP dosage is $70 \mathrm{mg} / \mathrm{m}^{2}{ }^{* *} \mathrm{P}<0.05$ vs. control, ${ }^{\# \#} \mathrm{P}<0.05$ vs. group CDDP (35). IHC, immunohistochemistry; VEGF, vascular endothelial growth factor; P450arom, aromatase P450; TGF- $\beta$, transforming growth factor- $\beta$; MMP-2, matrix metalloproteinase 2; CDDP, cisplatin. 
A

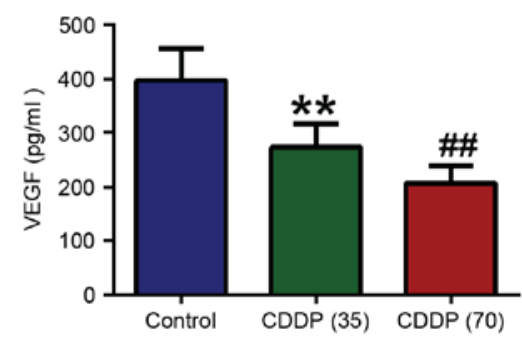

C

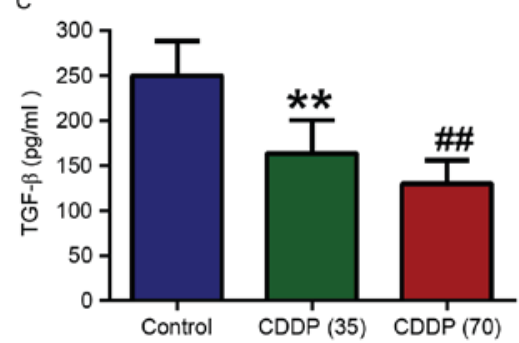

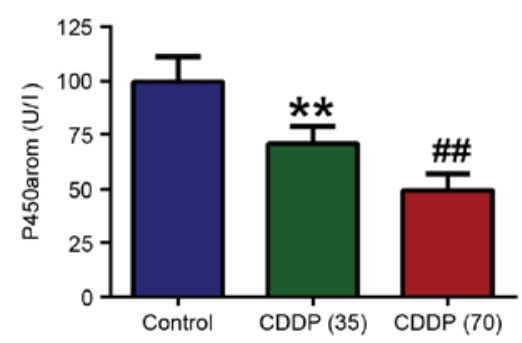

D

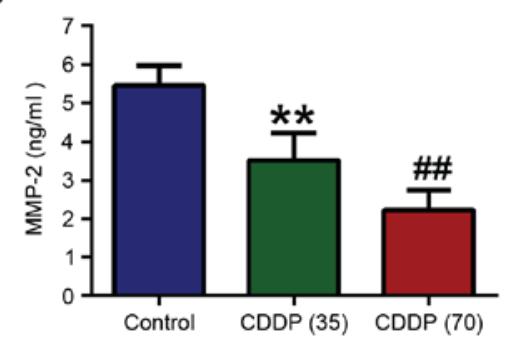

Figure 4. Comparisons of the VEGF, P450arom, TGF- $\beta$ and MMP-2 levels in the endometriotic tissues between the examined groups. The levels of (A) VEGF, (B) P450arom, (C) TGF- $\beta$ and (D) MMP-2 proteins in the endometriotic tissues were quantified with enzyme-linked immunosorbent assay kits. Data are presented as the mean \pm standard deviation. Control: Group 1; CDDP (35): Group 2, CDDP dosage is $35 \mathrm{mg} / \mathrm{m}^{2}$; CDDP (70): Group 3, CDDP dosage is $70 \mathrm{mg} / \mathrm{m}^{2} .{ }^{* *} \mathrm{P}<0.05$ vs. control, ${ }^{\# \#} \mathrm{P}<0.05$ vs. group CDDP (35). VEGF, vascular endothelial growth factor; P450arom, aromatase P450; TGF- $\beta$, transforming growth factor- $\beta$; MMP-2, matrix metalloproteinase 2; CDDP, cisplatin.

the VEGF levels in the peritoneal fluid were significantly lower in Groups $2(168.91 \pm 24.79 \mathrm{pg} / \mathrm{ml})$ and $3(115.27 \pm 19.50 \mathrm{pg} / \mathrm{ml})$ compared with Group $1(324.84 \pm 53.55 \mathrm{pg} / \mathrm{ml} ; \mathrm{P}<0.05)$. In addition, the decrease in the level of VEGF in peritoneal fluid was significant in Group 2 (from $289.37 \pm 12.30$ to $168.91 \pm 24.79 \mathrm{pg} / \mathrm{ml} ; \mathrm{P}<0.05$ ) and in Group 3 (from $275.16 \pm 27.19$ to $115.27 \pm 19.50 \mathrm{pg} / \mathrm{ml} ; \mathrm{P}<0.05$ ), while the VEGF level non-significantly increased in Group 1 (from $278.33 \pm 19.90$ to $324.84 \pm 53.55 \mathrm{pg} / \mathrm{ml}$; P>0.05; Table I). Following treatment, the VEGF, P450arom, TGF- $\beta$ and MMP-2 levels in endometriotic tissues were significantly reduced in Groups $2(272.83 \pm 43.76 \mathrm{pg} / \mathrm{ml}, 70.92 \pm 8.94 \mathrm{U} / \mathrm{l}$, $164.16 \pm 36.91 \mathrm{pg} / \mathrm{ml}$ and $3.52 \pm 0.72 \mathrm{pg} / \mathrm{ml}$; respectively) and $3(206.74 \pm 36.07 \mathrm{pg} / \mathrm{ml}, 49.16 \pm 7.90 \mathrm{U} / 1,130.09 \pm 28.72$ $\mathrm{pg} / \mathrm{ml}$ and $2.22 \pm 0.57 \mathrm{pg} / \mathrm{ml}$; respectively), compared with in Group $1(388.61 \pm 79.41 \mathrm{pg} / \mathrm{ml}, 99.45 \pm 11.73 \mathrm{U} / 1$, $250.63 \pm 37.69 \mathrm{pg} / \mathrm{ml}$ and $5.28 \pm 1.06 \mathrm{pg} / \mathrm{ml}$; respectively; $\mathrm{P}<0.05$; Fig. 4A-D). Furthermore, these levels were lower in Group 3 than in Group 2 following CDDP treatment. Comparison of the study groups is presented in Fig. 4A-D.

Western blot analysis of VEGF and P450arom. Western blot analysis of VEGF protein of the endometriotic tissues demonstrated similar results to the IHC results (Fig. 5A). The VEGF protein level in the endometriotic tissues were significantly reduced in Groups 2 and 3 compared with in Group $1(\mathrm{P}<0.05$; Fig. 5B). Western blot analysis of P450arom protein of the endometriotic tissues also demonstrated similar results to the IHC results (Fig. 5C). The P450arom protein levels in the endometriotic tissues were also significantly reduced in Groups 2 and 3, compared with Group 1 ( $\mathrm{P}<0.05$; Fig. 5D). In addition, the VEGF and P450arom levels were significantly lower in Group 3 compared with in Group $2(\mathrm{P}<0.05$; Fig. 5B and D).

\section{Discussion}

The rat model established by autologous transplantation of endometrial tissue has been used extensively in endometriosis research $(25,27,29,30)$. The advantages of this model are the low cost involved and the potential for genetic manipulation using transgenic animals for etiology studies (31-34). The endometriotic tissues of rats perform in a similar manner to human endometriotic tissues in organ explant culture, and the rat model is a valuable tool for the exploration of novel therapeutic medicines, permitting the research of pathogenesis and pathophysiology of endometriosis (35).

Blood vessels are necessary for the development and maintenance of endometriosis (36). Angiogenesis is essential for the development of a number of diseases, including cancer and endometriosis (37). Local angiogenesis is regulated by VEGF, which stimulates the proliferation and migration of vascular endothelial cells (38). The VEGF concentration in peritoneal fluid and endometriotic tissue has been reported to be increased in women with endometriosis (39-41).

Furthermore, TGF- $\beta$ also serves important roles in the control of cellular proliferation, differentiation and apoptosis (42). Evidence demonstrated that TGF- $\beta$ is produced by endometriotic lesions and could be involved in the establishment and progression of the disease $(42,43)$. The receptors and signaling pathways of these proteins may be altered in patients with endometriosis and these proteins may therefore be potential targets for the development of therapeutic agents (42). VEGF and TGF- $\beta$ are thought to be critical for the implantation and infiltration of ectopic endometrium, as well as the invasion and metastasis of ovarian tumor cells (44-47). In the present study, following the administration of CDDP, the regression of endometriotic implants was observed, along with a significant decrease in the VEGF level in the peritoneal fluid of rats. 
A

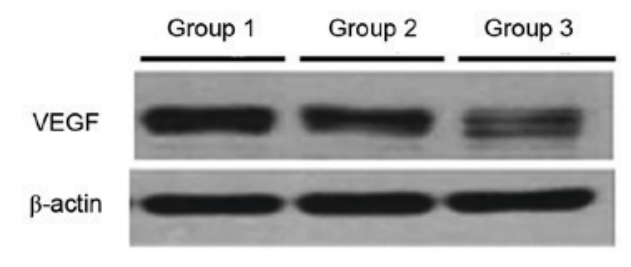

C

P450arom

$\beta$-actin

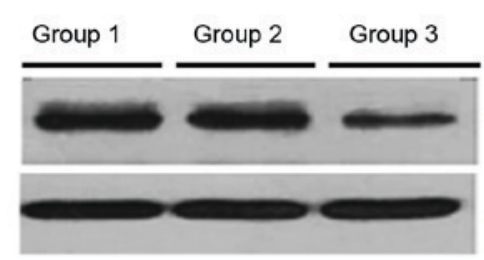

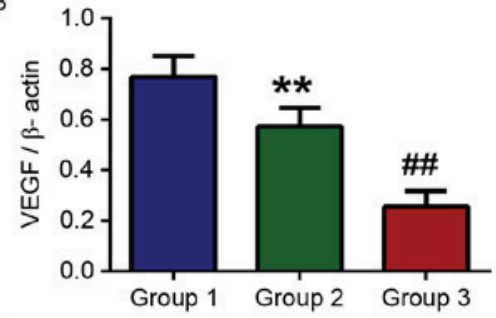

D

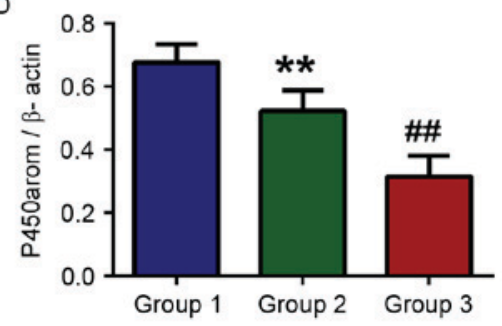

Figure 5. Protein levels of VEGF and P450arom in the endometriotic tissues of the model rats, as assessed by western blot analysis. Representative western blots of (A) VEGF with (B) quantification and (C) P450arom with (D) quantification. The expressions of VEGF and P450arom were downregulated in Groups 2 and 3 compared with the control group. ${ }^{* * *} \mathrm{P}<0.05$ vs. Group $1,{ }^{\# \#} \mathrm{P}<0.05$ vs. Group 2. VEGF, vascular endothelial growth factor; $\mathrm{P} 450$ arom, aromatase P450.

Furthermore, the protein expression of VEGF and TGF- $\beta$ in the endometriotic implants also decreased significantly. These results suggest that CDDP may be involved in the regression of the endometriotic lesions via suppression of cell proliferation and inhibition of the angiogenesis of endometriotic tissue.

MMPs and tissue inhibitor of metalloproteinases are critical factors in the breakdown of the extracellular matrix and remodeling of endometrial tissue in endometriosis (36). The overexpression of MMP-2 has been observed in patients with endometriosis (48). MMP-2 is involved in extracellular matrix disruption in the early angiogenic stage of vascular budding and sprouting (49). In the present study, the MMP-2 protein was principally detected in the mesenchymal cells, and its IHC expression level was significantly lower in the CDDP-treated groups when compared with the control group, which was corroborated by and was more evident in the ELISA results. Therefore, the effect of CDDP's on endometriotic implants may result from its suppression of MMP-2, which results in the inhibition of the breakdown of the extracellular matrix and remodeling of endometrial tissue in the progression of endometriosis in the rats, and this effect of CDDP may be combined with its suppression of VEGF and TGF- $\beta$; however, the exact mechanism and action of this association need to be further studied.

Endometriosis is widely accepted as an estrogen-dependent condition, the progression of which is strongly affected by the level of serum estrogen (50). Several studies have reported that endometriotic tissues express aromatase and synthesize their own estrogen (1,50-53). P450arom is the key enzyme for estrogen synthesis, and catalyzes the conversion of androstenedione and testosterone to estrone and estradiol (2). As aromatases are involved in the synthesis of estrogen, the application of aromatase inhibitors is a valuable advance in the treatment of endometriosis (54-56). In the present study, P450arom was principally detected in the glandular epithelial cells of the endometriotic implants, and the expression levels of the P450arom protein were significantly lower following CDDP treatment. The results of ELISA and western blot analyses were in concurrence with these results. This inhibitory effect of
CDDP on estrogen synthesis was in accordance with the function of aromatase inhibitors reported in a previous study (56). In addition, researchers have also demonstrated that CDDP chemotherapy is associated with effects on ovarian function in clinical and experimental animal studies $(57,58)$. These results suggest that CDDP may be involved in the regression of the endometriotic tissue in an estrogen-inhibiting manner.

The histopathological examination and protein expression analyses of endometriotic tissue in the present study demonstrated that angiogenesis-associated factors, including VEGF and TGF- $\beta$, and the extracellular matrix-disrupting protein MMP-2 are all downregulated following CDDP administration. Furthermore, the expression of the P450arom protein, which is crucial for estrogen synthesis, was also suppressed by CDDP. As a result, regression of the endometriotic implants and decrease in the histological scores were observed in the CDDP-treated groups.

In the present study, a dosage of $70 \mathrm{mg} / \mathrm{m}^{2} \mathrm{CDDP}$ was administered every 4 days, which corresponds with the chemotherapy dosage administered for ovarian cancer and endometrial cancer in clinical practice, a total of 4 rats in the CDDP-treated group exhibited loss of hair following treatment for 15 days. However, this was not observed in the group administered the lower dosage of $35 \mathrm{mg} / \mathrm{m}^{2} \mathrm{CDDP}$. Furthermore, a dose-dependent effect was observed in the regression and protein expression of the endometriotic tissues in the two CDDP-treated groups. These results imply that the CDDP dosage is a critical factor associated with its effects and side effects in the treatment of endometriosis and requires exploration in future studies. However, one should also take into consideration that CDDP is a drug which has a number of severe side effects, including severe kidney problems, allergic reactions, decrease immunity to infections, gastrointestinal disorders, hemorrhage and neurotoxicity $(14,19,59,60)$; particularly for CDDP's gonadal toxicity and the concern of reproductive function preservation (61). Therefore, it may be more appropriate to administer CDDP medication to cases with endometriosis refractory at the same time in clinical practice to conventional therapies for patients who have decided not to have 
more children ever. Balancing the benefits and risk of CDDP and the proper indications of CDDP treatment in endometriosis requires further study.

In the present study, rats were treated for a total of 24 days, which was equivalent to 6 estrous cycles of rat. This was based on the consideration that 6 courses (which equals 6 menstrual cycles of women) of chemotherapy is the standard treatment protocol for patients with ovarian cancer and endometrial cancer in clinical practice. To the best of our knowledge, the present study is the first to apply CDDP treatment in a surgically induced endometriosis rat model.

In conclusion, the present study demonstrated that CDDP causes significant regression of surgically induced endometriotic implants in model rats, and this effect is accompanied by a decrease in the expression of VEGF, P450arom, TGF- $\beta$ and MMP-2 in these tissues. CDDP exhibited promising therapeutic effects in the rat endometriosis model. Further animal and clinical studies should be conducted to determine whether CDDP may be used as an effective therapeutic option for the treatment of endometriosis.

\section{Acknowledgements}

The authors would like to thank Dr Li Yanf, Dr Li Xue Yuan, and Professor He Jun for their instructive advice and useful technical support on this research.

\section{Funding}

Peking Union Medical College Hospital financially supported this study.

\section{Availability of data and materials}

All data generated and analyzed during this study are included in this published article.

\section{Authors' contributions}

ZL and JL designed the study. ZL, HL, GZ and ZH were responsible for the collection, analysis and interpretation of data in the literature. ZL, HL and JL prepared the manuscript together and were involved in drafting the manuscript or revising it critically for important intellectual content. All authors read and approved the final manuscript.

\section{Ethics approval and consent to participate}

The present study was approved by the Institutional Animal Care and Use Committee of the Institute of Laboratory Animal Science, and the research was conducted in accordance with the institutional guidelines.

\section{Patient consent for publication}

Not applicable.

\section{Competing interests}

The authors declare that they have no competing interests.

\section{References}

1. Nothnick WB: The emerging use of aromatase inhibitors for endometriosis treatment. Reprod Biol Endocrinol 9: 87, 2011.

2. Bulun SE, Imir G, Utsunomiya H, Thung S, Gurates B, Tamura M and Lin Z: Aromatase in endometriosis and uterine leiomyomata. J Steroid Biochem Mol Biol 95: 57-62, 2005.

3. Bedaiwy MA, Allaire C and Alfaraj S: Long-term medical management of endometriosis with dienogest and with a gonadotropin-releasing hormone agonist and add-back hormone therapy. Fertil Steril 107: 537-548, 2017.

4. Surrey ES and Hornstein MD: Prolonged GnRH agonist and add-back therapy for symptomatic endometriosis: Long-term follow-up. Obstet Gynecol 99: 709-719, 2002.

5. Meng Q, Sun W, Jiang J, Fletcher NM, Diamond MP and Saed GM: Identification of common mechanisms between endometriosis and ovarian cancer. J Assist Reprod Genet 28: 917-923, 2011.

6. Wang S, Qiu L, Lang JH, Shen K, Huang HF, Pan LY, Wu M, Yang JX and Guo LN: Prognostic analysis of endometrioid epithelial ovarian cancer with or without endometriosis: A 12-year cohort study of Chinese patients. Am J Obstet Gynecol 209: 241 e241-e249, 2013.

7. Li F, Tie R, Chang K, Wang F, Deng S, Lu W, Yu L and Chen M: Does risk for ovarian malignancy algorithm excel human epididymis protein 4 and CA125 in predicting epithelial ovarian cancer: A meta-analysis. BMC Cancer 12: 258, 2012.

8. Augoulea A, Alexandrou A, Creatsa M, Vrachnis N and Lambrinoudaki I: Pathogenesis of endometriosis: The role of genetics, inflammation and oxidative stress. Arch Gynecol Obst 286: 99-103, 2012.

9. Olovsson M: Immunological aspects of endometriosis: An update. Am J Reprod Immunol 66 (Suppl 1): S101-S104, 2011.

10. Ogawa S, Kaku T, Amada S, Kobayashi H, Hirakawa T, Ariyoshi K, Kamura T and Nakano H: Ovarian endometriosis associated with ovarian carcinoma: A clinicopathological and immunohistochemical study. Gynecol Oncol 77: 298-304, 2000.

11. Somigliana E, Vigano P, Parazzini F, Stoppelli S, Giambattista E and Vercellini P: Association between endometriosis and cancer: A comprehensive review and a critical analysis of clinical and epidemiological evidence. Gynecol Oncol 101: 331-341, 2006.

12. Vlahos NF, Kalampokas T and Fotiou S: Endometriosis and ovarian cancer: A review. Gynecol Endocrinol 26: 213-219, 2010.

13. Aris A: Endometriosis-associated ovarian cancer: A ten-year cohort study of women living in the Estrie Region of Quebec, Canada. J Ovarian Res 3: 2, 2010.

14. Brinton LA, Lamb EJ, Moghissi KS, Scoccia B, Althuis MD, Mabie JE and Westhoff CL: Ovarian cancer risk associated with varying causes of infertility. Fertil Steril 82: 405-414, 2004.

15. Siufi Neto J, Kho RM, Siufi DF, Baracat EC, Anderson KS and Abrao MS: Cellular, histologic, and molecular changes associated with endometriosis and ovarian cancer. J Minim Invasive Gynecol 21: 55-63, 2014.

16. Zhao C, Wu LS and Barner R: Pathogenesis of ovarian clear cell adenofibroma, atypical proliferative (borderline) tumor, and carcinoma: Clinicopathologic features of tumors with endometriosis or adenofibromatous components support two related pathways of tumor development. J Cancer 2: 94-106, 2011.

17. Bookman MA: Optimal primary therapy of ovarian cancer. Ann Oncol 27 (Suppl 1): i58-i62, 2016.

18. da Costa Miranda V, de Souza Fêde ÂB, Dos Anjos CH, da Silva JR, Sanchez FB, da Silva Bessa LR, de Paula Carvalho J, Filho EA, de Freitas D and Del Pilar Estevez Diz M: Neoadjuvant chemotherapy with six cycles of carboplatin and paclitaxel in advanced ovarian cancer patients unsuitable for primary surgery: Safety and effectiveness. Gynecol Oncol 132: 287-291, 2014.

19. Yu X, Zheng H, Chan MT and Wu WK: Modulation of chemoresponsiveness to platinum-based agents by microRNAs in cancer. Am J Cancer Res 7: 1769-1778, 2017.

20. Wang QE, Milum K, Han C, Huang YW, Wani G, Thomale J and Wani AA: Differential contributory roles of nucleotide excision and homologous recombination repair for enhancing cisplatin sensitivity in human ovarian cancer cells. Mol Cancer 10: 24, 2011.

21. Woo MG, Xue K, Liu J, McBride $H$ and Tsang BK: Calpain-mediated processing of p53-associated parkin-like cytoplasmic protein (PARC) affects chemosensitivity of human ovarian cancer cells by promoting p53 subcellular trafficking. J Biol Chem 287: 3963-3975, 2011.

22. Ingelmo JM, Quereda F and Acien P: Effect of human interferon-alpha-2b on experimental endometriosis in rats: Comparison between short and long series of treatment. Eur J Obst Gynecol Reprod Biol 167: 190-193, 2013. 
23. Sun J, Jin C, Wu H, Zhao J, Cui Y, Liu H, Wu L, Shi Y and Zhu B: Effects of electro-acupuncture on ovarian P450arom, P450c17a and mRNA expression induced by letrozole in PCOS rats. PLoS One 8: e79382, 2013.

24. Simsek Y, Celik O, Karaer A, Gul M, Yılmaz E, Koc O, Colak C, Zengin S and Aydin NE: Therapeutic efficiency of Atosiban, an oxytocin receptor blocking agent in the treatment of experimental endometriosis. Arch Gynecol Obstet 286: 777-783, 2012.

25. Körbel C, Menger MD and Laschke MW: Size and spatial orientation of uterine tissue transplants on the peritoneum crucially determine the growth and cyst formation of endometriosis-like lesions in mice. Hum Reprod 25: 2551-2558, 2010.

26. Spiers DE and Candas V: Relationship of skin surface area to body mass in the immature rat: A reexamination. J Appl Physio Respir Environ Exerc Physiol 56: 240-243, 1984.

27. Ceyhan ST, Onguru O, Fidan U, Ide T, Yaman H, Kilic S and Baser I: Comparison of aromatase inhibitor (letrozole) and immunomodulators (infliximab and etanercept) on the regression of endometriotic implants in a rat model. Eur J Obstet Gynecol Reprod Biol 154: 100-104, 2011.

28. Keenan JA, Williams-Boyce PK, Massey PJ, Chen TT, Caudle MR and Bukovsky A: Regression of endometrial explants in a rat model of endometriosis treated with the immune modulators loxoribine and levamisole. Fertil Steril 72: 135-141, 1999.

29. Edwards AK, Nakamura DS, Virani S, Wessels JM and Tayade C: Animal models for anti-angiogenic therapy in endometriosis J Reprod Immunol 97: 85-94, 2013.

30. Li Z, Liu H, He Z, Zhang G and Lang J: Effects of cisplatin and letrozole on surgically induced endometriosis and comparison of the two medications in a rat model. Eur J Pharm Sci 93: 132-140, 2016.

31. Stanic AK, Kim M, Styer AK and Rueda BR: Dendritic cells attenuate the early establishment of endometriosis-like lesions in a murine model. Reprod Sci 21: 1228-1236, 2014.

32. Aydin Y, Atis A, Uludag S, Tezer I, Sakiz D, Acar H and Toklu A: Remission of endometriosis by hyperbaric oxygen treatment in rats. Reprod Sci 18: 941-947, 2011.

33. Mansour G, Sharma RK, Agarwal A and Falcone $T$ : Endometriosis-induced alterations in mouse metaphase II oocyte microtubules and chromosomal alignment: A possible cause of infertility. Fertil Steril 94: 1894-1899, 2010.

34. Chen QH, Zhou WD, Pu DM, Huang QS, Li T and Chen QX: 15-Epi-lipoxin A(4) inhibits the progression of endometriosis in a murine model. Fertil Steril 93: 1440-1447, 2010.

35. Sharpe-Timms KL: Using rats as a research model for the study of endometriosis. Ann NY Acad Sci 955: 318-406, 2002.

36. Osteen KG, Yeaman GR and Bruner-Tran KL: Matrix metalloproteinases and endometriosis. Semin Reprod Med 21: 155-164, 2003.

37. Griffioen AW and Molema G: Angiogenesis: Potentials for pharmacologic intervention in the treatment of cancer, cardiovascular diseases, and chronic inflammation. Pharmacol Rev 52: 237-268, 2000

38. Ozer H, Boztosun A, Acmaz G, Atilgan R, Akkar OB and Kosar MI: The efficacy of bevacizumab, sorafenib, and retinoic acid on rat endometriosis model. Reprod Sci 20: 26-32, 2013.

39. Machado DE, Abrao MS, Berardo PT, Takiya CM and Nasciutti LE: Vascular density and distribution of vascular endothelial growth factor (VEGF) and its receptor VEGFR-2 (Flk-1) are significantly higher in patients with deeply infiltrating endometriosis affecting the rectum. Fertil Steril 90: 148-155, 2008

40. McLaren J, Prentice A, Charnock-Jones DS and Smith SK: Vascular endothelial growth factor (VEGF) concentrations are elevated in peritoneal fluid of women with endometriosis. Hum Reprod 11: 220-223, 1996.

41. Donnez J, Smoes P, Gillerot S, Casanas-Roux F and Nisolle M: Vascular endothelial growth factor (VEGF) in endometriosis. Hum Reprod 13: 1686-1690, 1998.

42. Dela Cruz C and Reis FM: The role of TGF $\beta$ superfamily members in the pathophysiology of endometriosis. Gynecol Endocrinol 31: 511-515, 2015.
43. Zhang Q, Duan J, Liu X and Guo SW: Platelets drive smooth muscle metaplasia and fibrogenesis in endometriosis through epithelial-mesenchymal transition and fibroblast-to-myofibroblast transdifferentiation. Mol Cell Endocrinol 428: 1-16, 2016

44. Rein DT, Schmidt T, Bauerschmitz G, Hampl M, Beyer IM, Paupoo AA, Curiel DT and Breidenbach M: Treatment of endometriosis with a VEGF-targeted conditionally replicative adenovirus. Fertil Steril 93: 2687-2694, 2010.

45. Mohamed ML, El Behery MM and Mansour SA: Comparative study between VEGF-A and CA-125 in diagnosis and follow-up of advanced endometriosis after conservative laparoscopic surgery. Arch Gynecol Obstet 287: 77-82, 2013.

46. Perini JA, Cardoso JV, Berardo PT, Vianna-Jorge R, Nasciutti LE, Bellodi-Privato M, Machado DE and Abrão MS: Role of vascular endothelial growth factor polymorphisms (-2578C $>\mathrm{A},-460$ $\mathrm{T}>\mathrm{C},-1154 \mathrm{G}>\mathrm{A},+405 \mathrm{G}>\mathrm{C}$ and $+936 \mathrm{C}>\mathrm{T}$ ) in endometriosis: $\mathrm{A}$ case-control study with Brazilians. BMC Womens Health 14: 117,2014

47. Tamburro S, Canis M, Albuisson E, Dechelotte P, Darcha C and Mage G: Expression of transforming growth factor betal in nerve fibers is related to dysmenorrhea and laparoscopic appearance of endometriotic implants. Fertil Steril 80: 1131-1136, 2003.

48. Huang HF, Hong LH, Tan Y and Sheng JZ: Matrix metalloproteinase 2 is associated with changes in steroid hormones in the sera and peritoneal fluid of patients with endometriosis. Fertil Steril 81: 1235-1239, 2004.

49. Carmeliet P: Mechanisms of angiogenesis and arteriogenesis. Nat Med 6: 389-395, 2000.

50. Bulun SE: Endometriosis. N Engl J Med 360: 268-279, 2009.

51. Burney RO and Giudice LC: Pathogenesis and pathophysiology of endometriosis. Fertil Steril 98: 511-519, 2012.

52. Bulun SE, Zeitoun KM, Takayama K and Sasano H: Molecular basis for treating endometriosis with aromatase inhibitors. Hum Reprod Update 6: 413-418, 2000.

53. Abu Hashim H: Potential role of aromatase inhibitors in the treatment of endometriosis. Int J Womens Health 6: 671-680, 2014.

54. Ailawadi RK, Jobanputra S, Kataria M, Gurates B and Bulun SE: Treatment of endometriosis and chronic pelvic pain with letrozole and norethindrone acetate: A pilot study. Fertil Steril 81: 290-296, 2004

55. Abushahin F, Goldman KN, Barbieri E, Milad M, Rademaker A and Bulun SE: Aromatase inhibition for refractory endometriosis-related chronic pelvic pain. Fertil Steril 96: 939-942, 2011.

56. Oner G, Ozcelik B, Ozgun MT, Serin IS, Ozturk F and Basbug M: The effects of metformin and letrozole on endometriosis and comparison of the two treatment agents in a rat model. Hum Rep 25: 932-937, 2010

57. Li X, Kang X, Deng Q, Cai J and Wang Z: Combination of a GnRH agonist with an antagonist prevents flare-up effects and protects primordial ovarian follicles in the rat ovary from cisplatin-induced toxicity: A controlled experimental animal study. Reprod Biol Endocrinol 11: 16, 2013.

58. Blumenfeld Z, Avivi I, Linn S, Epelbaum R, Ben-Shahar M and Haim N: Prevention of irreversible chemotherapy-induced ovarian damage in young women with lymphoma by a gonadotrophin-releasing hormone agonist in parallel to chemotherapy. Hum Reprod 11: 1620-1626, 1996.

59. Dasari S and Tchounwou PB: Cisplatin in cancer therapy: Molecular mechanisms of action. Eur J Pharmacol 740: 364-378, 2014.

60. Ruggiero A, Trombatore G, Triarico S, Arena R, Ferrara P, Scalzone M, Pierri F and Riccardi R: Platinum compounds in children with cancer: Toxicity and clinical management. Anticancer Drugs 24: 1007-1019, 2013.

61. Chahvar ST, Al-Shawaf T and Tranquilli AL: Pharmacologic ovarian preservation in young women undergoing chemotherapy. Curr Med Chem 21: 223-229, 2014. 